\title{
Recent advances in the recognition and management of eosinophilic esophagitis
}

\author{
Gregory Eustace MD, Xianyong Gui MD, Marietta lacucci MD PhD
}

\begin{abstract}
G Eustace, X Gui, M Iacucci. Recent advances in the recognition and management of eosinophilic esophagitis. Can J Gastroenterol Hepatol 2015;29(5):237-240.

The incidence and recognition of eosinophilic esophagitis is increasing. Pathophysiological understanding of eosinophilic esophagitis is improving and an immunological reaction to ingested food is likely to play a significant role. Patients present with dysphagia and food bolus obstruction. Both histological and endoscopic criteria have been developed and validated. Dietary therapy, topical steroid therapy, proton pump inhibitors and endoscopic dilation are the main approaches to therapy; however, novel targeted therapies are being developed. Among the food items commonly implicated are wheat, dairy, nuts, soy, shellfish and eggs. A multidisciplinary approach to management in dedicated clinics may yield the best results.
\end{abstract}

Key Words: Endoscopic findings; Eosinophilic esophagitis

\section{Les récents progrès pour dépister et prendre en charge l'œesophagite à éosinophiles}

L'incidence et le dépistage de l'œsophagite à éosinophiles augmentent. On en comprend mieux la physiopathologie, et la réponse immunologique aux aliments ingérés y joue probablement un rôle important. Les patients présentent une dysphagie et une obstruction du bol alimentaire. Des critères histologiques et endoscopiques ont été mis au point et validés. Les principales approches thérapeutiques sont la thérapie diététique, le traitement aux stéroïdes, les inhibiteurs de la pompe à protons et la dilatation endoscopique, mais de nouvelles thérapies ciblées sont en cours d'élaboration. Parmi les aliments souvent en cause, soulignons le son, les produits laitiers, les noix, le soja, les fruits de mer et les œufs. Une prise en charge multidisciplinaire dans des cliniques spécialisées donnera peut-être les meilleurs résultats.

\section{DEFINITION AND EPIDEMIOLOGY}

Eosinophilic esophagitis (EoE) is a comparatively recent newcomer to the field of gastroenterology, with the first case described in literature by Landres et al (1) in 1978. Since then, its recognition as a clinically relevant and potentially manageable disorder has increased, first in pediatric and, more recently, in adult gastroenterology. EoE in adults is defined clinically by symptoms of esophageal dysfunction including dysphagia, reflux and food impaction $(2,3)$. Histologically, it is defined by an eosinophil-predominant inflammatory response (4). EoE was initially believed to be a rare disorder of childhood and has only been described in the adult literature since 1993. Since that time, however, likely due to both increased recognition and increasing incidence (5), the number of cases has surged dramatically. Dellon et al (6) conducted a large study involving $>35$ million individuals in the United States, with estimates of overall adult prevalence of EoE to be 56.7 per 100,000 . Other smaller studies have reported adult prevalences of anywhere from 23 per 100000 in a Swiss study (7) to 400 per 100,000 in a smaller study from Sweden (8). Regardless of the true number, there is little argument that the prevalence of EoE is significantly greater than anyone had realized even a decade ago, and that it will represent an expanding clinical challenge in the coming years. It is, therefore, important to optimize and standardize the recognition and management of EoE in adult gastroenterology practice.

\section{PATHOGENESIS}

While its pathogenesis remains largely under investigation, EoE is believed to be primarily an allergy-mediated disorder in response to ingested or inhaled antigens. It is not, however, a traditional immunoglobulin (Ig) E-mediated allergic response indicated by the lack of utility of traditional cutaneous allergy testing and the lack of resolution in patients treated with anti- $\operatorname{IgE}$ therapies $(9,10)$. It is not clear why these allergens produce a pathological response; however, there are theories proposing an impaired epithelial barrier in EoE patients because there is a demonstrated downregulation of the cell adhesion protein DSG-1 in active EoE that partially resolves with treatment (11).
This impaired barrier may facilitate the overexposure of antigen to professional antigen-presenting cells in the esophagus.

The allergic stimulus triggers a T-helper cell 2-mediated allergic response in the esophagus, with the release of interleukin (IL) 13 and IL4 $(12,13)$ - cytokines that act as mediators of several other allergic disorders such as asthma and atopic dermatitis. IL13 and IL4 then cause the esophageal epithelium to secrete eotaxin-3, a powerful chemoattractant that causes eosinophillic and mast cell migration to the esophageal epithelium (14). Another powerful chemoattractant, thymic stromal lymphopoietin, is found at higher concentrations in biopsies of EoE patients and its deletion in murine models eliminates EoE, thus supporting its role in the disease $(15,16)$.

Chronic eosinophillic infiltration and inflammation leads to tissue remodelling with deposition of fibrin, epithelial hyperplasia, abnormal angiogenesis and hypertrophy of the muscularis propria (17-21). IL13 and IL4 are also believed to play a direct role in remodelling by activating fibroblast and stellate cells and causing increased expression of matrix proteins $(13,22)$. Chronic remodelling results in the endoscopic findings characteristic of EoE including corrugated esophagus, linear furrowing and stricture formation (23-25). There is controversy regarding the relative involvement of $\mathrm{IgG}_{4}$ versus $\operatorname{IgE}(26)$.

\section{CLINICAL PRESENTATION}

Clinically, EoE presents with symptoms consistent with esophageal dysmotility and mechanical obstruction. Dysphagia, reflux and food impaction are the most common presenting complaints for adolescents and adults, while children can present with nonspecific features such as abdominal pain or failure to thrive (4). Several studies have shown that typical endoscopic features, when combined with clinical symptoms, other risk factors, such as an atopic history, can often discriminate EoE from mimics such as reflux esophagitis $(27,28)$. In a meta-analysis by Kim et al (29), at least one endoscopic abnormality (including esophageal rings, strictures, narrow-calibre esophagus, linear furrows, white plaques, and pallor or decreased vasculature) was observed in $92 \%$ of patients with EoE, the most common of which were esophageal rings and linear furrows.

Division of Gastroenterology, Department of Medicine, University of Calgary, Calgary, Alberta

Correspondence: Dr Marietta Iacucci, Division of Gastroenterology, Department of Medicine, University of Calgary, 2500 University Drive Northwest,

Calgary, Alberta T2N 1N4. Telephone 403-592-5015, fax 403-592-5090, e-mail miacucci@ucalgary.ca

Received for publication March 31, 2015. Accepted April 1, 2015 

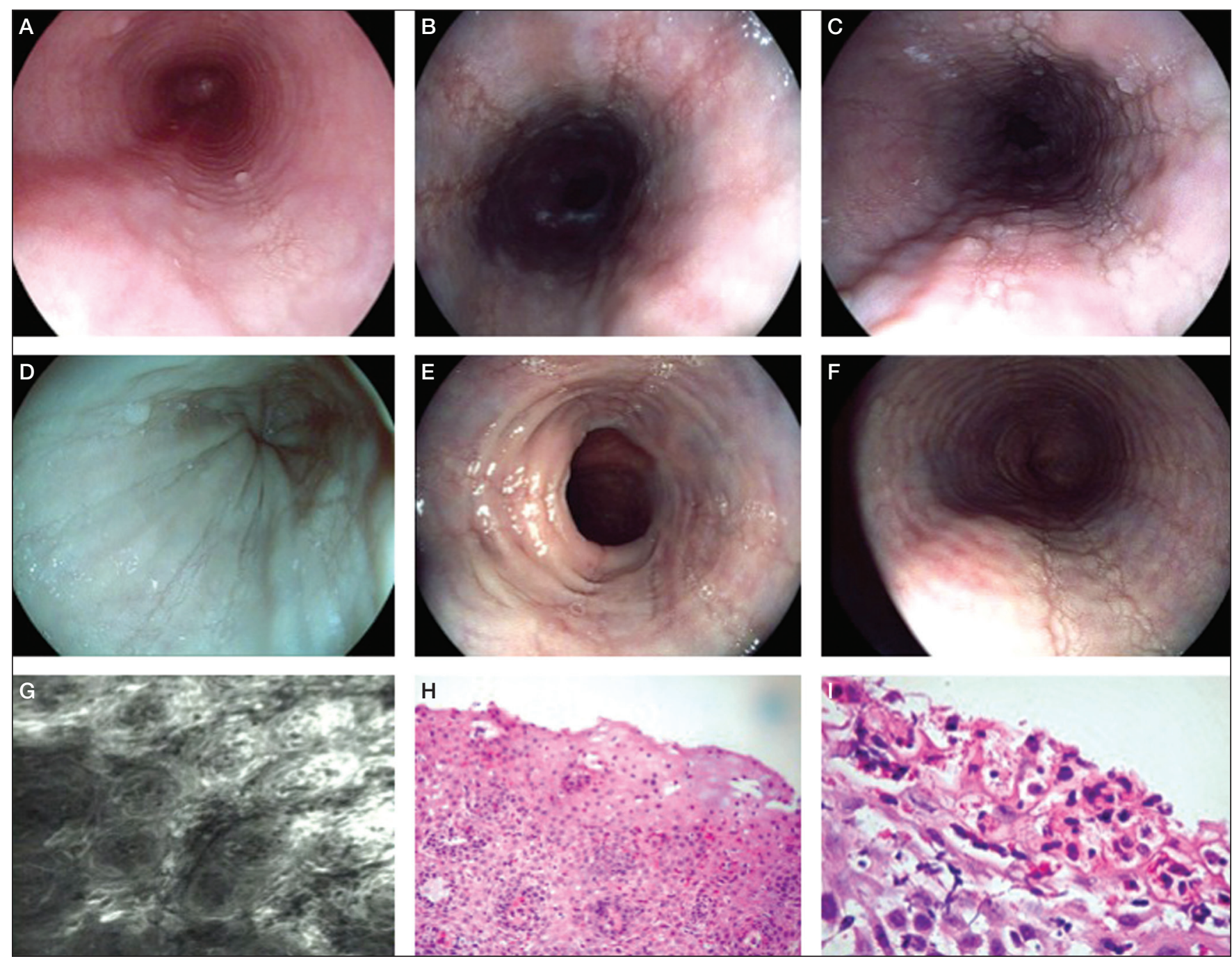

Figure 1) A High-definition endoscopy showing linear vertical furrows with subtle circumferential rings. B to D iSCAN (Pentax, USA) virtual chromoendoscopy better define linear furrows and characterize the white exudate as mild disease. $\mathrm{E}$ and $\mathrm{F}$ iSCAN virtual chromoendoscopy characterizes the rings as severe disease. $\mathrm{G}$ Confocal laser endomicroscopy showing dilated intercellular spaces with microabscess and leakage of fluorescein. $\mathrm{H}$ and I Hematoxylin and eosin stain (original magnification $\times 200-400$ ) showing large number of intraepithelial eosinophilis as well as basal cell hyperplasia, spongiosis and microabscesses

\section{DIAGNOSIS}

While there are certainly suggestive characteristics endoscopically, traditional diagnosis still relies on histology of biopsies obtained at endoscopy. Before the landmark review of EoE by Furuta et al (30) in 2007 , there was little consensus as to the precise diagnostic parameters for the disease. The Furuta review delineated clear criteria including histology showing $>15$ eosinophils per high-power field in $\geq 1$ biopsies, clinical symptoms and the exclusion of gastroesophageal reflux disease (GERD) as the cause for eosinophilia. Evolving knowledge has led to evolving guidelines, with the most recent changes in 2011 recognizing the uncertainty around EoE by establishing a new clinically distinct entity known as proton pump inhbitor-responsive EoE (PPI-REE). This new category recognizes that there are patients with EoE-like disease, as opposed to GERD, which does respond well to PPI therapy (4). This uncertainty arises from the fact that, despite clear diagnostic criteria, the distinguishing line between EoE and GERD is not always clinically very clear. Numerous studies have demonstrated an eosinophilic infiltrate in GERD patients and, in fact, because of the huge prevelance of GERD, the majority of patients with an eosinophilic infiltrate are likely to have GERD rather than EoE (31). Adding to this uncertainty is the recognition that EoE disease can be patchy and individual biopsies may miss affected areas (32). In fact, biopsy technique is another evolving area of research. In terms of location of biopsy, earlier reports suggested focusing on the distal esophagus. Current practice, however, suggests obtaining biopsies from the middle and distal esophagus to minimize confusion with reflux esophagitis. The ideal number of biopsies remains unclear, with a study by Gonsalves et al (33) demonstrating sensitivities of biopsies from 55\% to $100 \%$ for one and five biopsies, respectively. A recent study by Nielsen et al (34) suggests four biopsies from the mid and distal esophagus with no increased sensitivity beyond six biopsies.

The reason many clinicians are uncomfortable with diagnostic uncertainty in EoE is that it has been shown to be a progressive disease, with often irreversible fibrotic and stenotic changes that accumulate in untreated patients. Delays in diagnosis have dire consequences for patients, as shown in a study by Schoepfer et al (35) in 2013. Percentages of patients suffering from stricturing disease rose from $17 \%$ when diagnosed within two years of onset to $>70 \%$ when there were delays in diagnosis of $>20$ years. Another study by Dellon et al (36) showed the risk of fibrostenotic disease doubling for every 10 years of disease progression.

The typical findings at endoscopy of EoE include esophageal rings, linear furrows, exudates, pallor, loss of vasculature, mucosal fragility and strictures (36). In 2011, a study by Hirano et al (37) investigating the intra-observer validity of various endoscopic features, fixed rings/strictures, exudates, furrows and edema had the best predictive value for an eventual EoE diagnosis. These endoscopic 
findings have become the hallmarks of EoE and should prompt biopsies and further diagnostic workup during routine endoscopy. However, some of the features may be subtle and easily missed and, in 5\% to $10 \%$ of patients, the endoscopy may be described as normal. Obtaining multiple biopsies from at least two locations, such as proximal and distal esophagus, is essential in any patient with suspected EoE, regardless of endoscopic findings. A validated $\mathrm{EoE}$ endoscopic reference score has recently been described, which may be used in clinical trials as well as in clinical practice to longitudinally follow-up patients with EoE. It is known as the EoE endoscopic reference score (EREFS), the acronym also reflects the major components of the score: exudates, rings, edema, furrows and strictures (37).

Narrow-band magnifying endoscopy may also enable visualization of the fine capillary patterns and other subtle abnormalities that can help in the diagnosis of EoE (38). The appearances of EoE on confocal endomicroscopy has been described (39). Given the patchy nature of involvement, endoscopy with biopsies may miss the involved areas and confocal endomicroscopy may provide further help in localizing the disease and obtaining targeted biopsies. In addition, a tethered capsule confocal endomicroscopy has been described, which may help in the diagnosis and follow-up of EoE (40) (Figure 1).

\section{THERAPY}

As the recognition of EoE and understanding of its pathophysiology develops, so do novel therapeutic approaches. To date, the cornerstones of treatment have been exclusion diets and topical swallowed steroids along with PPIs for PPI-REE and endoscopic dilation for strictures or rings. Exclusion diets rely on the assumption of ingested antigens triggering an eosinophil-predominant inflammation and their use has been mostly studied in the pediatric population. Several variations of dietary therapy have been evaluated including amino acid-based formula diets, the 'six food' exclusion diet (dairy, eggs, peanuts, soy, wheat and shellfish) and diets tailored to individual allergens; all have shown degrees of success (9,41-43). These diets appear to have more utility in pediatric populations, in which adherence to strict diets are more feasible. One of the problems of exclusion diets are the strategy for reintroduction of food items without requiring esophageal biopsies. In adult EoE, swallowed topical steroids are the current treatment of choice. Fluticasone inhalers are commonly used as a swallowed medication at doses from $440 \mu \mathrm{g}$ to $880 \mu \mathrm{g}$ twice daily. Preparations of viscous budesonide are equally effective (44) but are often a challenge to obtain. In randomized controlled trials, topical steroids have been shown to be effective in reducing both the clinical symptoms and endoscopic changes in EoE (45). New evidence suggests they may also reverse the remodelling process caused by chronic inflammation (46). Unfortunately, numerous studies have shown that the benefits of treatment stop with discontinuation, usually within several months (45). Strictures may not resolve on medical therapy alone and esophageal dilation may be necessary to improve dysphagia rapidly. Esophageal dilation does not carry any higher risk of perforation than esophageal dilation of benign strictures in the absence of EoE.

While exclusion diets are difficult to maintain and the prospect of chronic steroids often unattractive for both prescribers and patients, focus has shifted to novel therapies. IL5 and IL13 have been the subject of targeted, biologic-based therapy for EoE, with the former having undergone more clinical trials. As previously outlined, IL5 is one of the major cytokines implicated in the pathogenesis of EoE. To date, four studies have investigated anti-IL5 molecules (mepolizumab and rezlizumab) as therapies for EoE. Although all studies demonstrated a reduction in intraepithelial eosinophil counts, a significant clinical improvement was not demonstrated (47-51). Experimental anti-IL13 antibodies have been developed for use primarily in asthma and inflammatory bowel disease; however, one clinical trial is investigating its role in EoE (Efficacy and Safety of QAX576 in Patients With Eosinophilic Esophagitis). Results of this study are not yet published.

\section{CONCLUSIONS}

In the future, it is important to focus on early therapy to prevent irreversible complications and adherence to therapy to maintain remission, as well as develop targeted therapies and dietary interventions to modify the disease course. Specific clinics to manage and follow up EoE and nurse practitioners to implement protocolbased therapies will become important. Multidisciplinary care is very relevant, with involvement of gastroenterologists and pathologists with an interest in $\mathrm{EoE}$, and allergists and dieticians.

DISCLOSURES: The authors have no financial disclosures or conflicts of interest to declare.

\section{REFERENCES}

1.Landres RT, Kuster GG, Strum WB. Eosinophilic esophagitis in a patient with vigorous achalasia. Gastroenterology 1978;74:1298-301.

2. Ferre-Ybarz L, Nevot Falco S, Plaza-Martin AM. Eosinophilic oesophagitis: Clinical manifestations and treatment options. The role of the allergologist. Allergol Immunopathol (Madr) 2008;36:358-65.

3. Sgouros SN, Bergele C, Mantides A. Eosinophilic esophagitis in adults: A systematic review. Eur J Gastroenterol Hepatol 2006;18:211-7.

4. Liacouras CA, Furuta GT, Hirano I, et al. Eosinophilic esophagitis: Updated consensus recommendations for children and adults. J Allergy Clin Immunol 2011;128:3-20.e6.

5. Hruz P, Straumann A, Bussmann C, et al. Escalating incidence of eosinophilic esophagitis: A 20-year prospective, population-based study in Olten county, Switzerland. J Allergy Clin Immunol 2011;128:1349-50.e5.

6. Dellon ES, Jensen ET, Martin CF, Shaheen NJ, Kappelman MD. The prevalence of eosinophilic esophagitis in the United States. Clin Gastroenterol Hepatol 2014;12:589-96.e1.

7. Ronkainen J, Talley NJ, Aro P, et al. Prevalence of oesophageal eosinophils and eosinophilic oesophagitis in adults: The populationbased Kalixanda study. Gut 2007;56:615-20.

8. Straumann A, Simon HU. Eosinophilic esophagitis: Escalating epidemiology? J Allergy Clin Immunol 2005;115:418-9.

9. Gonsalves N, Yang GY, Doerfler B, Ritz S, Ditto AM, Hirano I. Elimination diet effectively treats eosinophilic esophagitis in adults; food reintroduction identifies causative factors. Gastroenterology 2012;142:1451-9.e1

10. Rocha R, Vitor AB, Trindade E, et al. Omalizumab in the treatment of eosinophilic esophagitis and food allergy. Eur J Pediatr 2011;170:1471-4

11. Blanchard C, Wang N, Stringer KF, et al. Eotaxin-3 and a uniquely conserved gene-expression profile in eosinophilic esophagitis. J Clin Invest 2006;116:536-47.

12. Straumann A, Bauer M, Fischer B, Blaser K, Simon HU Idiopathic eosinophilic esophagitis is associated with a $\mathrm{T}(\mathrm{H}) 2$-type allergic inflammatory response. J Allergy Clin Immunol 2001;108:954-61.

13. Zuo L, Fulkerson PC, Finkelman FD, et al. IL-13 induces esophageal remodeling and gene expression by an eosinophil-independent, IL-13R alpha 2-inhibited pathway. J Immunol 2010;185:660-9.

14. Straumann A, Kristl J, Conus S, et al. Cytokine expression in healthy and inflamed mucosa: Probing the role of eosinophils in the digestive tract. Inflamm Bowel Dis 2005;11:720-6.

15. Noti M, Wojno ED, Kim BS, et al. Thymic stromal lymphopoietinelicited basophil responses promote eosinophilic esophagitis. Nat Med 2013;19:1005-13.

16. Soumelis V, Reche PA, Kanzler H, et al. Human epithelial cells trigger dendritic cell mediated allergic inflammation by producing TSLP. Nat Immunol 2002:3:673-80.

17. Aceves SS, Ackerman SJ. Relationships between eosinophilic inflammation, tissue remodeling, and fibrosis in eosinophilic esophagitis. Immunol Allergy Clin North Am 2009;29:197-211.

18. Aceves SS. Tissue remodeling in patients with eosinophilic esophagitis: What lies beneath the surface? J Allergy Clin Immunol 2011;128:1047-9

19. Lucendo AJ, Arias A, De Rezende LC, et al. Subepithelial collagen deposition, profibrogenic cytokine gene expression, and changes 
after prolonged fluticasone propionate treatment in adult eosinophilic esophagitis: A prospective study. J Allergy Clin Immunol 2011;128:1037-46.

20. Mueller S, Aigner T, Neureiter D, Stolte M. Eosinophil infiltration and degranulation in oesophageal mucosa from adult patients with eosinophilic oesophagitis: A retrospective and comparative study on pathological biopsy. J Clin Pathol 2006;59:1175-80.

21. Potter JW, Saeian K, Staff D, et al. Eosinophilic esophagitis in adults: An emerging problem with unique esophageal features. Gastrointest Endosc 2004;59:355-61.

22. Merves J, Muir A, Modayur Chandramouleeswaran P, et al. Eosinophilic esophagitis. Ann Allergy Asthma Immunol 2014;112:397-403.

23. Fox VL, Nurko S, Teitelbaum JE, Badizadegan K, Furuta GT. High-resolution EUS in children with eosinophilic "allergic" esophagitis. Gastrointest Endosc 2003;57:30-6.

24. Schoepfer AM, Gonsalves N, Bussmann C, et al. Esophageal dilation in eosinophilic esophagitis: Effectiveness, safety, and impact on the underlying inflammation. Am J Gastroenterol 2010;105:1062-70.

25. Stevoff C, Rao S, Parsons W, Kahrilas PJ, Hirano I. EUS and histopathologic correlates in eosinophilic esophagitis. Gastrointest Endosc 2001;54:373-7.

26. Clayton F, Fang JC, Gleich GJ, et al. Eosinophilic esophagitis in adults is associated with IgG4 and not mediated by $\operatorname{lgE}$. Gastroenterology 2014;147:602-9.

27. Dellon ES, Gibbs WB, Fritchie KJ, et al. Clinical, endoscopic, and histologic findings distinguish eosinophilic esophagitis from gastroesophageal reflux disease. Clin Gastroenterol Hepatol 2009;7:1305-13.

28. Mulder DJ, Hurlbut DJ, Noble AJ, Justinich CJ. Clinical features distinguish eosinophilic and reflux-induced esophagitis. J Pediatr Gastroenterol Nutr 2013;56:263-70.

29. Kim HP, Vance RB, Shaheen NJ, Dellon ES. The prevalence and diagnostic utility of endoscopic features of eosinophilic esophagitis: A meta-analysis. Clin Gastroenterol Hepatol 2012;10:988-96.e5.

30. Furuta GT, Liacouras CA, Collins MH, et al; First International Gastrointestinal Eosinophil Research Symposium (FIGERS) Subcommittees. Eosinophilic esophagitis in children and adults: A systematic review and consensus recommendations for diagnosis and treatment. Gastroenterology 2007;133:1342-63.

31. Rodrigo S, Abboud G, Oh D, et al. High intraepithelial eosinophil counts in esophageal squamous epithelium are not specific for eosinophilic esophagitis in adults. Am J Gastroenterol 2008;103:435-42.

32. Yantiss RK, Odze RD. Optimal approach to obtaining mucosal biopsies for assessment of inflammatory disorders of the gastrointestinal tract. Am J Gastroenterol 2009;104:774-83.

33. Gonsalves N, Policarpio-Nicolas M, Zhang Q, Rao MS, Hirano I. Histopathologic variability and endoscopic correlates in adults with eosinophilic esophagitis. Gastrointest Endosc 2006;64:313-9.

34. Nielsen JA, Lager DJ, Lewin M, Rendon G, Roberts CA. The optimal number of biopsy fragments to establish a morphologic diagnosis of eosinophilic esophagitis. Am J Gastroenterol 2014;109:515-20.

35. Schoepfer AM, Safroneeva E, Bussmann C, et al. Delay in diagnosis of eosinophilic esophagitis increases risk for stricture formation in a time-dependent manner. Gastroenterology 2013;145:1230-6.e1-2.
36. Dellon ES, Kim HP, Sperry SL, Rybnicek DA, Woosley JT, Shaheen NJ. A phenotypic analysis shows that eosinophilic esophagitis is a progressive fibrostenotic disease. Gastrointest Endosc 2014;79:577-85.e4.

37. Hirano I, Moy N, Heckman MG, Thomas CS, Gonsalves N, Achem SR. Endoscopic assessment of the oesophageal features of eosinophilic oesophagitis: Validation of a novel classification and grading system. Gut 2013;62:489-95.

38. Tanaka K, Rubio CA, Dlugosz A, et al. Narrow-band imaging magnifying endoscopy in adult patients with eosinophilic esophagitis/esophageal eosinophilia and lymphocytic esophagitis. Gastrointest Endosc 2013;78:659-64.

39. Neumann H, Vieth M, Atreya R, Mudter J, Neurath MF. First description of eosinophilic esophagitis using confocal laser endomicroscopy (with video). Endoscopy 2011;(43 Suppl 2): UCTN:E66.

40. Tabatabaei N, Kang D, Wu T, et al. Tethered confocal endomicroscopy capsule for diagnosis and monitoring of eosinophilic esophagitis. Biomed Opt Express 2013;5:197-207.

41. Kagalwalla AF, Sentongo TA, Ritz S, et al. Effect of six-food elimination diet on clinical and histologic outcomes in eosinophilic esophagitis. Clin Gastroenterol Hepatol 2006;4:1097-102.

42. Spergel JM, Andrews T, Brown-Whitehorn TF, Beausoleil JL, Liacouras CA. Treatment of eosinophilic esophagitis with specific food elimination diet directed by a combination of skin prick and patch tests. Ann Allergy Asthma Immunol 2005;95:336-43.

43. Arias A, Lucendo AJ. Dietary therapies for eosinophilic esophagitis. Expert Rev Clin Immunol 2014;10:133-42.

44. Straumann A, Conus S, Degen L, et al. Budesonide is effective in adolescent and adult patients with active eosinophilic esophagitis. Gastroenterology 2010;139:1526-37,1537.e1.

45. Konikoff MR, Noel RJ, Blanchard C, et al. A randomized, doubleblind, placebo-controlled trial of fluticasone propionate for pediatric eosinophilic esophagitis. Gastroenterology 2006;131:1381-91.

46. Aceves SS, Newbury RO, Chen D, et al. Resolution of remodeling in eosinophilic esophagitis correlates with epithelial response to topical corticosteroids. Allergy 2010;65:109-16.

47. Helou EF, Simonson J, Arora AS. 3-yr-follow-up of topical corticosteroid treatment for eosinophilic esophagitis in adults. Am J Gastroenterol 2008;103:2194-199.

48. Straumann A, Conus S, Grzonka P, et al. Anti-interleukin-5 antibody treatment (mepolizumab) in active eosinophilic oesophagitis: A randomised, placebo-controlled, double-blind trial. Gut 2010;59:21-30.

49. Stein ML, Collins MH, Villanueva JM, et al. Anti-IL-5 (mepolizumab) therapy for eosinophilic esophagitis. J Allergy Clin Immunol 2006;118:1312-9.

50. Assa'ad AH, Gupta SK, Collins MH, et al. An antibody against IL-5 reduces numbers of esophageal intraepithelial eosinophils in children with eosinophilic esophagitis. Gastroenterology 2011;141:1593-604.

51. Spergel JM, Rothenberg ME, Collins MH, et al. Reslizumab in children and adolescents with eosinophilic esophagitis: Results of a double-blind, randomized, placebo-controlled trial. J Allergy Clin Immunol 2012;129:456-63,463.e1-3. 


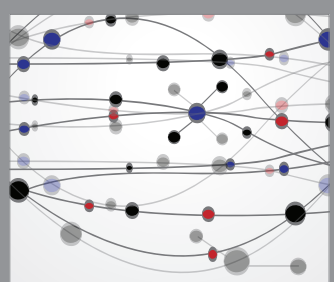

The Scientific World Journal
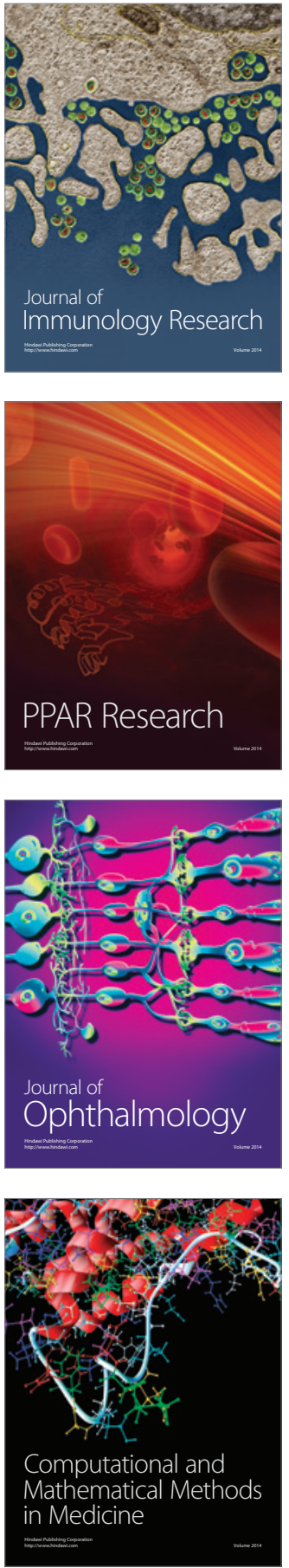

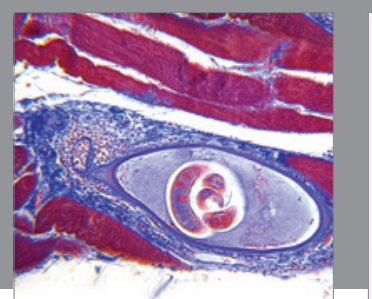

Gastroenterology Research and Practice

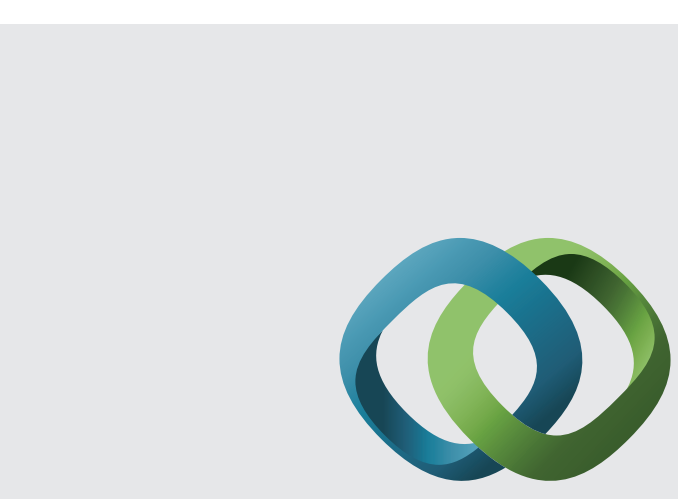

\section{Hindawi}

Submit your manuscripts at

http://www.hindawi.com
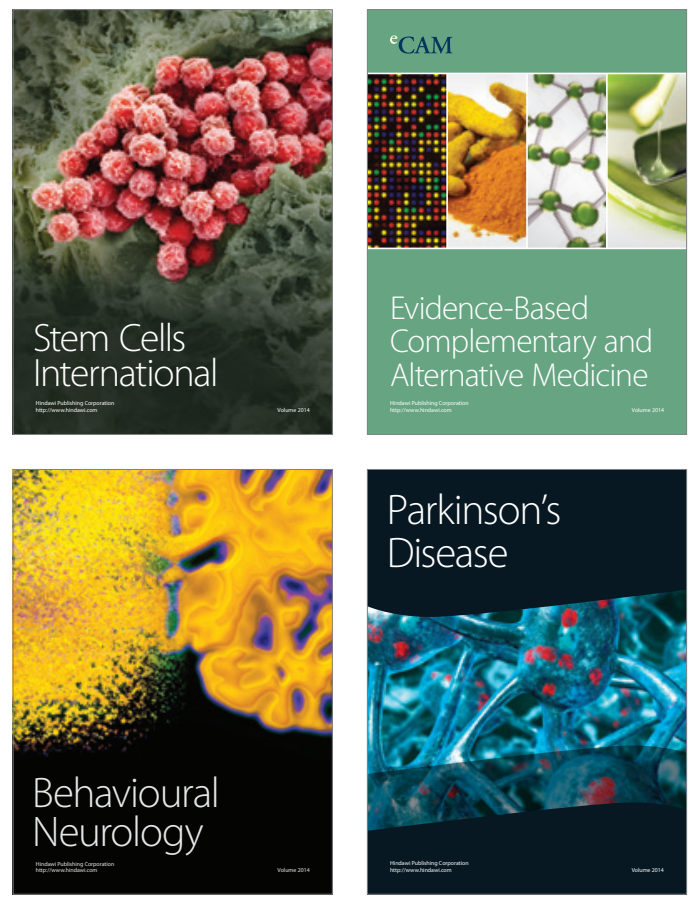
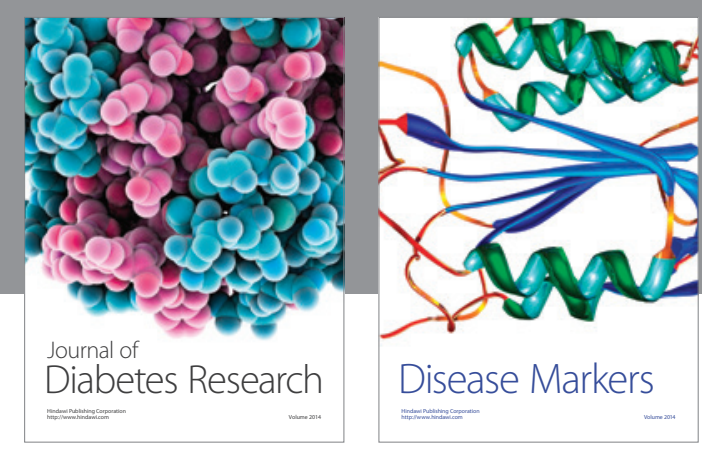

Disease Markers
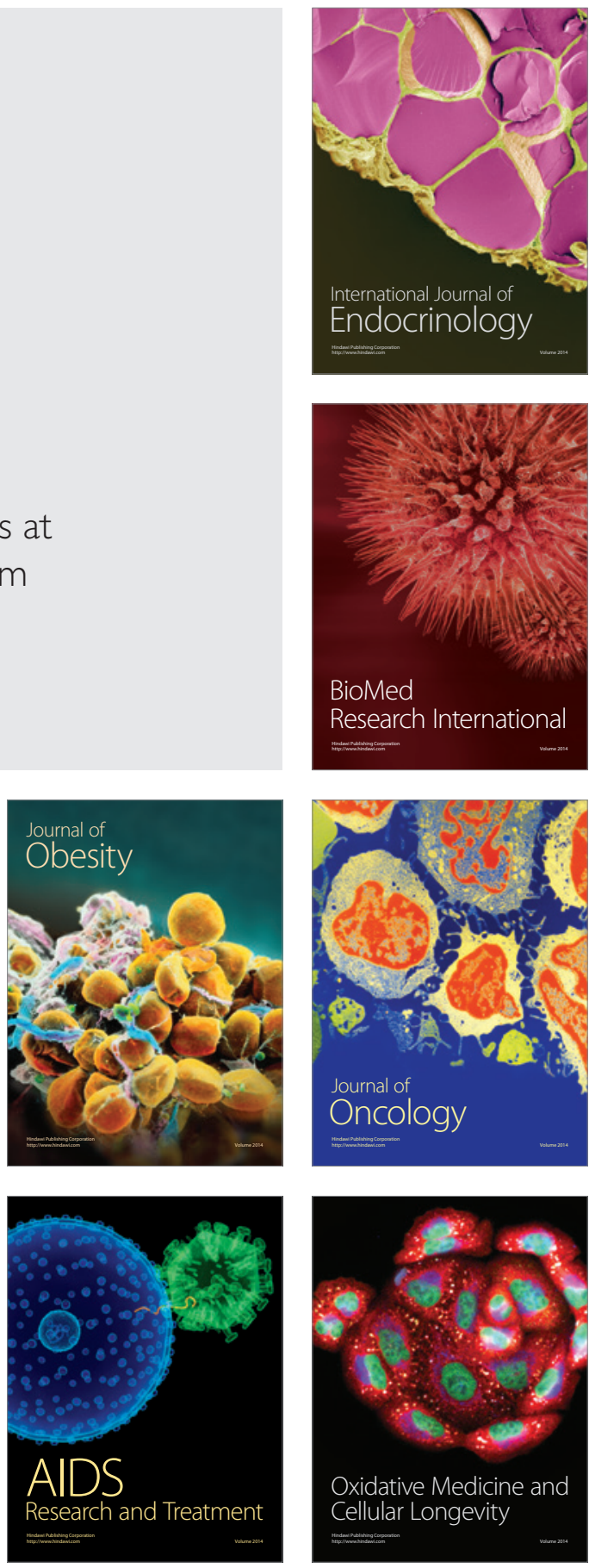